\title{
Medios, regímenes de creencia $y$ formas de vida
}

\author{
Jacques Fontanille \\ (Université de Limoges - Institut Universitaire de France)
}

Recibido: 24/4/2013

Aprobado: 30/5/2013

\begin{abstract}
Resumen: Este texto, escrito en homenaje a Eric Landowski, no trata sobre la sociosemiótica de Landowski ni es un texto a propósito de Eric. Quiere ser solamente un texto «para» Eric Landowski. Se habla aquí de los medios, que a veces le han interesado en una perspectiva sociosemiótica; y nos esforzamos por hacerlo sin mucha jerga y sin tecnicismos, que con frecuencia lo han irritado con nosotros, semiotistas. Hablamos aquí de nuestra condición de hombres y de interpretantes sometidos a todas las manipulaciones, que es su preocupación principal, e intentamos hacerlo sobre el horizonte de una exigencia ética, que es su marca de fábrica.
\end{abstract}

Palabras clave: Semiosfera / integración / prácticas / creencia / formas de vida

\section{Media, modes of belief and forms of life}

Aвstract: This text, written in tribute to Eric Landowski is not about Landowski's socio-semiotic, neither is a text about Eric. This text aims to be a text «for» Eric Landowski. We discuss about media here, which sometimes have been of his interest from the perspective of socio-semiotics; we strive to discuss without using too much jargon and technicisms, which have often annoyed him among us, semioticians. We discuss here about our condition of men and interpreters subject to all kind of manipulations, manipulations that have been Landowski's main concern; and we try to discuss upon the horizon of an ethical demand, ethics that are Landowski's trademark.

Keywords: Semiosphere / integration / practices / beliefs / forms of life 
Para Eric Landowski

\section{Para comenzar: la semiosfera y los medios}

$\mathrm{P}$ lantear la cuestión de la influencia de los medios en la cultura contemporánea implica algunas consideraciones previas que se imponen a toda indagación de envergadura, sean de la naturaleza que fuesen, y sobre las cuales la aproximación semiótica está en capacidad de trazar algunas pistas de reflexión. La mayor parte de ellas tocan el lugar de los medios en la arquitectura semiótica de las culturas.

Los trabajos de la semiótica de las culturas, particularmente los de la Escuela de Tartu-Moscú, parten de una hipótesis general y original, condensada en el concepto de semiosfera (Lotman 1999), según la cual una cultura se define por sus interacciones con otras culturas en el curso de un «diálogo»y de intercambios de formas culturales de una y otra parte de una frontera simbólica: de este lado de la frontera se despliega una cultura del «nosotros», y del otro lado, la cultura de «ellos», la alteridad cultural. De cierta manera, la semiosfera reproduce a escala colectiva lo que la fenomenología y la semiótica han descrito, a escala individual, como la estructura fundamental de toda experiencia sensible; a saber, la experiencia de intercambios entre el Mí (el universo de las emociones e impresiones internas), el Sí (la frontera simbólica del cuerpo propio) y el Otro (el mundo sensible, incluidos los otros cuerpos).

La semiosfera está organizada en torno a un centro (la zona de mayor coherencia y de la identidad cultural más fuertemente asumida, rodeada de zonas periféricas en las que esa coherencia y esa identidad se atenúan poco a poco, alejándose del centro. La periferia es la zona de intercambios con la cultura del otro, la zona de la heterogeneidad y de las formas culturales transitorias, eventualmente en curso de integración y de adaptación a la cultura de «nosotros». La diferencia entre las formas semióticas centrales y las periféricas tiene que ver principalmente con la manera como son asumidas por el «nosotros» y con la intensidad con la cual ese «nosotros» adhiere a las formas culturales. Esta intensidad se aprecia en términos de fuerza de compromiso, de estabilidad en el tiempo, de creencias compartidas, y es sostenida por numerosos dispositivos culturales destinados a legitimar esa fuerza, esa estabilidad y esas creencias: por ejemplo, en la zona central se despliegan y se imponen tradiciones, normas, géneros y cánones estéticos; en la zona periférica, en cambio, dominan los procesos de innovación, de traducción, de préstamo y de hibridación, que confieren un brillo y un valor muy particular a los aportes extraños, justamente en razón de su extrañeza y de su novedad. Por consiguiente, las «creencias» periféricas son de una naturaleza totalmente diferente que las 
del centro de la semiosfera, puesto que no están sostenidas ni por la tradición ni por el consenso, y por ningún dispositivo cultural institucionalizado; $\mathrm{y}$, justamente, valen por el contraste con la novedad, con la rareza o con la alteridad.

A este respecto, la posición de los medios es claramente periférica; $\mathrm{y}$, de algún modo, «por definición». Un medio, cualquiera sea la acepción particular de ese término, es siempre una instancia de puesta en relación entre al menos dos dominios disjuntos (etimológicamente «un ámbito intermediario»), y los medios contemporáneos lo son, también, en el sentido del «pasaje» entre dominios socioculturales. Ese rol mediador es frecuentemente comprendido por reducción como una función de comunicación (los medios son «soportes de comunicación»), pero bien se ve que en la perspectiva de la semiótica de las culturas, juegan necesariamente, en cuanto operadores de mediación, un rol decisivo en las zonas periféricas de la cultura, un rol de pasaje, de transferencia, de traslado, de traducción y de transformaciones de formas semióticas.

Desde ese punto de vista, la particular mundialización de las producciones mediáticas, en razón de la organización económica de ese sector de actividad, refuerza ese rol, y ancla aun más fuertemente los medios en las zonas periféricas de las culturas. De hecho, va más allá del mero «diálogo» bilateral considerado por Iuri Lotman, líder de la Escuela de Tartú (Lotman 1999: 21 y ss.) entre la cultura del «nosotros» y cada una de las culturas de «ellos», las culturas copartícipes. Los medios mundializados, en efecto, implican de inmediato la cultura del «nosotros» en una interacción multilateral, plural, incluso universal, con todas las otras culturas a la vez, incluidas aquellas que por razones geográficas e históricas, parecerían no poder mantener ninguna relación bilateral con la cultura del «nosotros».

Los medios someten, pues, el «centro» identitario de la cultura del «nosotros» a un verdadero asalto de informaciones y de significaciones venidas del mundo entero, diseminando en él, por olas sucesivas y periódicas, nuevos aportes y nuevas formas semióticas. Ese «asalto» apunta a la zona central, la que soporta la identidad propia de cada cultura particular. Como la zona central es también la de las creencias asumidas colectivamente de modo más fuerte, la cuestión de los regímenes mediáticos de creencia resulta primordial: su difusión en cada cultura los confronta a los que ya ocupan un lugar ahí y que, fundados en tradiciones o en instituciones específicas, son susceptibles de resistirlos, de repelerlos, pero también de acogerlos, de transformarlos y de asimilarlos, a riesgo de desestabilizar la identidad cultural del «nosotros».

Examinaremos, pues, con la mayor atención, la posición particular de los medios en la jerarquía y en el sistema de 
formas semióticas que constituyen las culturas, para tratar de comprender en qué y hasta qué punto su influencia puede transformar estas últimas. Luego, habiendo tomado en cuenta el carácter determinante de los regímenes de creencia, pondremos en evidencia la naturaleza de las confrontaciones previsibles entre los que se encuentran en los medios en general, y particularmente en los medios mundializados, de una parte, y los que ya están comprendidos en las instituciones simbólicas de cada cultura, de otra parte. Hecho esto, y paralelamente, desarrollaremos la noción de «forma de vida», y nos esforzaremos por captar cuales son los tipos de formas de vida que los medios contemporáneos instalan en nuestras culturas.

\section{Los medios, las culturas y las formas semióticas}

\section{Seis niveles de análisis de las culturas}

Cada cultura puede ser descrita y comprendida, en lo que concierne a las formas semióticas que la constituyen, desde muchos puntos de vista que caracterizan cada uno un nivel de objetos de análisis. En el estado actual de las investigaciones sobre esas cuestiones, se distinguen corrientemente seis niveles diferentes (Fontanille, 2008, cap. 1: 17-78): los signos, los textos, los objetos, las prácticas, las estrategias y las formas de vida; esta serie está regulada por un principio jerárquico y por procedimientos de integración.
Los signos son unidades elementales de significación (una palabra, un rostro, un logo) que forman cada uno un bloque que asocia a minima una expresión y un contenido. Ese mínimo es definido al menos por el hecho de que se puede aislar y hacer funcionar cada signo en numerosos contextos diferentes. En breve: un mínimo de significación dotado de una cierta autonomía que permite combinarlo con otros signos. Un punto de acción sobre un sitio de internet (un botón, un segmento de frase coloreada o señalada, etcétera) es típicamente un signo, compuesto por una expresión mínima que está asociada por convención a una función y a una acción también mínimas (hacer clic para abrir).

Los textos son conjuntos significantes compuestos, de naturaleza verbal, icónica (imágenes), gestual (lenguaje de sordomudos), etcétera. Se caracterizan por su clausura (planteada por principio de análisis) que permite localizar en ellos regularidades, recurrencias, contrastes; en suma, tipos de composiciones que llevan la significación de conjunto del texto. Por lo que concierne a las imágenes, por ejemplo, desde que se las considera como textos, y no solamente como asociaciones de signos icónicos, se les puede reconocer una «dimensión plástica» global, una composición visual estructurada que es en sí misma globalmente significante. En un titular de prensa, la maqueta de portada es típicamente de naturaleza textual, es decir, a la vez plástica, tabular y topológica: 
grafismos, tipografías, colores, formas de encartes, emplazamientos de fotos concurren todos, en efecto, a la identidad del titular de prensa, así como a una precodificación del contenido de los artículos, con vistas a guiar o a modular el recorrido visual y la lectura. La clausura textual permite, además, conferir un sentido particular al inicio y al fin del despliegue textual: la significación de un relato, por ejemplo, puede entonces ser deducida de la diferencia observable entre la situación final y la situación inicial.

Los objetos son entidades semióticas de tres dimensiones, caracterizadas por su estructura material, por su morfología exterior, y por algunas propiedades dinámicas que les confieren una «energía»: como mínimo, su peso, y más allá, todas las posibilidades de movimiento, tal como han sido previstas o no en el momento de su formación o de su concepción.

Para que un objeto pueda ser considerado como un «objeto significante», y no solamente como una "cosa», su estructura material, su morfología y su dinámica deben poder ser interpretadas en términos funcionales: son entonces determinantes de su «función» y de sus usos prácticos. El objeto es, en efecto, por definición, una «cosa» formada y destinada a usos identificables gracias a sus propiedades observables; un simple canto rodado puesto sobre un número de cartas responde a esta definición: una materia mineral, una forma suave y redondeada, un peso que asegura estabilidad; de todo lo cual se infiere una función y un uso de fijación.

Los medios son también, necesariamente, «objetos», con frecuencia muy sofisticados (el libro, el sitio de internet, etcétera), materiales o virtuales, pero dotados todos de propiedades técnicas capaces de asegurar la conservación, la legibilidad, la movilidad y la fiabilidad de los textos y de los signos que soportan.

Tal como los signos son directamente integrables en los textos, los objetos también son integrables en las prácticas, gracias a su función. Pero igualmente es necesario que los textos puedan ser integrados en los objetos, y que estos puedan ser configurados por la acogida de aquellos: en esta perspectiva, los objetos se convierten en soportes de los textos, soportes de su inscripción, de su conservación material y de su transmisión; es entonces la morfología de su envoltura superficial la que es adaptada a la función soporte, y esta adaptación de la envoltura de los objetos a la acogida de textos es, en particular, el fundamento de la escritura, que, en sentido estricto, pertenece también al universo mediático. El ejemplo de la portada de prensa, ya evocado, se orienta igualmente en ese sentido, puesto que la organización tabular, plástica y topológica de la página constituye una suerte de rejilla formal que, proyectada sobre la plana soporte (el objeto material), le proporciona una capacidad de acogida para 
la inscripción de los textos y de las imágenes, pero también un poder de guía y de manipulación de las prácticas de lectura.

Las prácticas son cursos de acción, que son principalmente definidas por el tema de la acción en curso, y por los diferentes roles que ese tema exige para que la acción tenga lugar: una conversación es una práctica que tiene por tema el intercambio de enunciados verbales y mimogestuales, que demanda al menos dos interlocutores y se despliega suscitando significaciones sociopragmáticas, incluso psicosociales y etnológicas. La propiedad principal de una práctica consiste en no estar cerrada: abierto en los dos términos de la cadena, el curso de acción debe encontrar su significación en el detalle de sus peripecias, en los acondicionamientos y las adaptaciones que la práctica debe operar para franquear los obstáculos, para negociar las dificultades y los azares, y para poder, en suma, continuar su curso. Una práctica puede tener un inicio y un fin, pero ese inicio y ese fin no participan de la significación de conjunto. Y si se les considera como significantes, eso implica que se trata la práctica como un texto; una sesión de navegación en internet tiene, necesariamente, un inicio y un fin, pero raras son las sesiones en las que los límites iniciales y finales son significativos. Cuando ese es el caso, la sesión se cuenta entonces como una búsqueda narrativa, con un potencial de dramatización muy parti- cular; pero la mayor parte del tiempo las prácticas mediáticas son difícilmente dramatizables, y se puede decir de su fin lo que Montaigne decía de la muerte: no es la «meta» de la vida, es solamente su extremidad.

A un nivel superior, las prácticas se combinan y se superponen para constituir estrategias. Las estrategias aportan específicamente un «horizonte» de valores dominantes (en nombre de los cuales las prácticas son ordenadas y dispuestas entre sí), así como un «estilo» estratégico, es decir, una cierta manera observable y caracterizable de tratar las relaciones entre las prácticas y de ajustarlas unas a otras. Si se supone, por ejemplo, que el desarrollo de una velada familiar obedece a una estrategia implícita, entonces se debe observar cómo y en nombre de qué las diferentes prácticas en las cuales los miembros de la familia están comprometidos son jerarquizadas, ordenadas y ajustadas las unas a las otras; por ejemplo, la identificación de la práctica dominante (la comida, la conversación, la televisión, etcétera), es decir, la que da ritmo y ordena a todas las demás, es con frecuencia la clave que permite comprender el estilo estratégico de la familia.

Hay una dimensión estratégica evidente en los medios desde el momento en que quienes los conciben tienen en cuenta situaciones concretas en las cuales las prácticas de uso se desenvuelven. Si se supone que el «espectador» promedio mira la televisión co- 
miendo, o teniendo una conversación con quienes están próximos, incluso yendo y viniendo entre los cuartos de la vivienda, y todo eso cambiando de canal de manera imprevisible, quien concibe la emisión del programa y la rejilla de programas deberá prever la gestión de esas competiciones entre prácticas superpuestas para asegurar un mínimo de continuidad en la audiencia.

Finalmente, se puede hablar de forma de vida cuando se identifican estilos estratégicos coherentes, recurrentes, relativamente independientes de las situaciones temáticas y suficientemente poderosos para influenciar todas las prácticas y todas las manifestaciones semióticas de un grupo o de un tipo social y cultural. La coherencia es la propiedad central de las formas de vida, pero una coherencia bien particular; en efecto, un texto es coherente desde que los mismos contenidos de significación son repetidos en muchos lugares del despliegue textual; asimismo, una práctica es coherente si conserva a lo largo de su curso el mismo objetivo; pero se trata ahí de la coherencia «horizontal», entre contenidos de la misma naturaleza y sobre un mismo nivel de análisis.

Una forma de vida obedece en cambio a un principio de coherencia «vertical», en un doble sentido: por el lado de los niveles de expresión, se observa una coherencia entre el tratamiento de los signos, de los textos, de las prácticas y de las estrategias inte- gradas a la forma de vida; por el lado de los niveles de contenido, se observa igualmente una coherencia entre los valores, los estilos, los roles, las cualidades sensibles, los ritmos, los regímenes temporales y las pasiones. Esta coherencia vertical de las formas de vida es, de hecho, una fuerte congruencia entre todas las opciones operadas sobre los diferentes niveles y sobre los diferentes tipos de contenidos que participan en una misma forma de vida. Veremos por qué los medios son particularmente apropiados para proponer nuevas formas de vida, pero también para degradarlas...

\section{Los niveles de análisis cultural de los medios}

Los niveles de análisis están ordenados jerárquicamente, según la serie precedente, de suerte que, como ya lo hemos sugerido, cada nivel superior acoge y reconfigura los elementos de los niveles inferiores, pero añadiéndole elementos que le son propios: por ejemplo, una práctica semiótica puede acoger y reconfigurar en conjunto signos, textos, objetos, para hacer de ellos elementos e instrumentos de un curso de acción. Si se considera esta disposición jerárquica en el otro sentido, comenzando por los niveles superiores, entonces se constata que estos últimos pueden igualmente ser integrados en los niveles inferiores, donde son manifestados según las reglas de ese nivel de acogida: por ejemplo, una práctica puede ser convertida en texto, o ser 
integrada en un texto, bajo la forma de un discurso de instrucción, o de modo de empleo; una forma de vida puede ser convertida en práctica, o ser integrada en una práctica: así, la fe religiosa, y toda la forma de vida que le está asociada, pueden ser reducidas y condensadas en la sola práctica de la oración.

Esas capacidades de integración (en el sentido ascendente o en el sentido descendente) son susceptibles de producir formas semióticas mixtas, que no son, sin embargo, ni incoherentes ni heterogéneas. Existen, por consiguiente, objetos de análisis que no están estrictamente situados en un nivel de análisis único, y que no son puramente textos, objetos o prácticas. Los medios, como ya se habrá comprendido, participan de esas formas mixtas, puesto que los hemos encontrado en todos los escalones de la cultura.

Si tomamos, por ejemplo, el caso de la televisión, en cuanto medio que asocia principalmente textos vídeos, configurados en programas y series de emisiones, con un soporte técnico (el canal de difusión), y prácticas de uso (diferentes formas del espectáculo y del consumo televisivos). El conocimiento de las prácticas y de los usos es necesario para comprender cómo está configurado el soporte: en efecto, a partir de esas prácticas y de esos usos será definida la rejilla de una cadena de televisión, el lugar y el tipo de cada programa y de cada emisión, pero también la publicidad y los enlaces; en breve, eso que se llama «rejilla» es la manera mediante la cual el soporte material es adaptado, por un lado, para recibir los textos $y$, por el otro, para controlar los usos. Equivale, en ese sentido, a la portada de la prensa escrita (cf. supra).

El «medio» es, en sentido restringido, un medio de mediación y de difusión; pero esta restricción no resiste por mucho tiempo el análisis, puesto que si se define ese «medio» como un soporte configurado a la vez con vistas a la acogida de textos y con vistas a la realización de las prácticas, ese soporte se convierte, por ese mismo hecho, en un «objeto» semiótico complejo e inextricablemente ligado a la mayor parte de los otros niveles de análisis: determina, en efecto, a la vez géneros $\mathrm{y}$ tipos de textos que puede acoger $\mathrm{y}$ los géneros y tipos de prácticas con las cuales es compatible. El medio es el mensaje, pero no exactamente en el sentido en el que lo entendía McLuhan: el medio es un objeto-soporte fuertemente estructurado y constreñido, que selecciona otras formas semióticas, hacia abajo (textos vídeos) y hacia arriba (prácticas y estrategias).

Pero ese poder estructurante, en el caso de los medios, se entiende mejor aun por razones institucionales y económicas. En efecto, la televisión en cuanto medio está organizado en «cadenas», tal como la prensa escrita está organizada en «títulos de prensa», periódicos y magacines, incluso en «grupos de prensa». Una cadena es 
una marca, una identidad comercial y estratégica, que, por un lado, tiene un estatuto jurídico y comercial, y que, por el otro, ha sido construido para definir modos y estilos de enunciación aplicables al conjunto de programas, emisiones y textos vídeos. Con ese título, remite a signos típicos (monogramas y logos), a mapas gráficos (que rigen la dimensión plástica de la textualidad visual), a una concepción dominante de los programas más importantes (prime time), así como «emisiones de flujo», $\mathrm{y}$, en consecuencia, prácticas de uso esperadas por los espectadores; adopta, como se ha visto, estrategias en relación con las prácticas de sus usuarios y de sus concurrentes.

Lo que está en juego en esas modulaciones y en esas elecciones, que alcanzan al conjunto de la arquitectura semiótica de la cultura (y de la jerarquía de niveles de análisis), es la posibilidad de proporcionar a la cadena una identidad y un estilo semiótico reconocibles, y por eso, todas esas modulaciones y todas esas elecciones deben dar una impresión de continuidad y coherencia. Es el momento de recordar que ese tipo de coherencia «vertical» es característica de esos conjuntos significantes a los que llamamos «formas de vida». Así, pues, una cadena de televisión propone globalmente una o muchas formas de vida. De ahí que se define por la fuerza aparente del lazo que une todas las decisiones que toma, por la congruencia que asegura entre todos los niveles de análisis, entre to- dos los tipos de contenidos, y cuanto mayor es la fuerza de esa congruencia, más fácil resulta de identificar y más se impone su identidad como legítima a los ojos del espectador.

El medio es, pues, un tipo semiótico fuertemente integrador en el seno de las culturas, en dos tiempos; primer tiempo: el de la constitución del soporte en cuanto configuración de acogida de textos mediáticos, por un lado, y, por otro, de las prácticas de sus usuarios; segundo tiempo: el de la institucionalización del soporte en cuanto «marca», cuya influencia semiótica se extiende luego desde los signos hasta las formas de vida. Ciertamente, no es el único que puede integrar así todas las dimensiones semióticas de la cultura; por lo demás, desempeña ese rol de poco tiempo a esta parte. En ciertos aspectos, desde un punto de vista semiótico, tiene el mismo poder estructurante e integrador para las culturas que la política, la arquitectura o el urbanismo.

Iuri Lotman ha mostrado notablemente cómo y por qué la ciudad de San Petersburgo, por su arquitectura y por su concepción urbanística, era la manifestación de una forma de vida, que implicaba el sentido de la historia y del tiempo, el de la política y los espacios sociales, el de la soberanía y su rol en la cultura en la época de Pedro el Grande (Lotman 1999: 124-146). De cierta manera, el dispositivo semiótico de la arquitectura es el mismo que el de los medios: textos y objetos (la me- 
moria histórica, los edificios), que hay que disponer sobre un objeto-soporte (la organización urbana), cuyo poder estructurante se extiende, por un lado, hasta los signos, y, por el otro, hasta las estrategias políticas y las formas de vida. Los medios no son, pues, los únicos que disponen de ese poder de integración semiótica, pero los términos de la comparación (la organización de una ciudad, el discurso político soberano, etcétera) dan la justa medida del alcance de su poder. Queda por comprender más específicamente cómo los medios contemporáneos juegan ese rol.

\section{Regímenes de creencia, pasiones y formas de vida}

\section{A cada tipo semiótico, su régimen de creencia}

Cada uno de los niveles de análisis distinguidos hasta aquí implica modalidades particulares de expresión, pero también de interpretación, y corresponden igualmente a un dominio de experiencia (corporal, sensible y cognitiva) bien específico. Las modalidades de interpretación dependen principalmente de la manera como cada uno de esos tipos semióticos pone en relación el universo de sentido y el tipo de expresión que propone con la experiencia sensible y cognitiva sobre la que se funda.

Por lo que concierne a los objetossoportes, la experiencia a la que remi- te su tipo de expresión tridimensional, así como sus tres propiedades (cf. supra: materia, morfología, dinámica) es la de los cuerpos, cuerpos físicos cualesquiera, pero también cuerpos vivientes. Más precisamente, esa experiencia sensible y cognitiva está aquí constituida por todas las interacciones de nuestro cuerpo propio con los otros cuerpos, un conjunto de interacciones entre morfologías de envoltura, estructuras materiales y tipos dinámicos. Esta experiencia deja huellas y recuerdos, proporciona aprendizajes, y puede así ser reactualizada con ocasión de la interpretación de un nuevo objeto.

Interrogarse sobre la ergonomía de un nuevo objeto es tratar de interpretar su forma con referencia a la memoria de las interacciones pasadas con objetos comparables, pero también, por anticipación, con el tipo de interacción que se podrá tener con él; interrogarse sobre el diseño de un objeto es tratar de encontrar en la morfología de superficie de ese objeto formas de experiencia vinculadas con el uso y con las funciones de otros objetos comparables. En suma, cierto régimen de creencia se instala en la confrontación entre lo que propone el nuevo objeto para interpretar y las experiencias acumuladas en memoria; ese régimen de creencia tiene el estatuto de una promesa (proporcionada por la forma semiótica) y de una aceptación de la promesa (que resulta de la confrontación con las huellas de la experiencia); en el corazón de 
esa promesa más o menos aceptada se desarrolla un diálogo entre dos cuerpos, el cuerpo propio del intérprete y el cuerpo-objeto propuesto.

De la misma manera, pero con mayor alcance, el dispositivo de persuasión y de interpretación propio de los medios implicará también una confrontación entre promesas y experiencias. Con la diferencia de que, como hemos visto, el alcance de la influencia de los medios se extiende a la totalidad de niveles de la cultura. Y entonces surge el problema cultural central, el de la congruencia (o no congruencia) de las promesas.

\section{Cruces, hibridación y conflictos de los regímenes de creencia}

En efecto, cada nivel de análisis propone sus propias promesas; y el conjunto de niveles de análisis controlados por un medio propone también una promesa global. La característica más sorprendente, en los medios contemporáneos, radica en la dificultad de asegurar la congruencia entre esos diferentes tipos de promesas semióticas, y más particularmente en los medios más difundidos y globalizados, la televisión e internet.

Si uno se detiene, por ejemplo, en el nivel de análisis de los textos, verbales, icónicos o vídeos, se puede observar que en sí mismos comportan promesas semióticas, a veces erigidas en contratos de lectura, que predeterminan la manera como se supone que el receptor las va a interpretar; en las culturas institucionalizadas, esas promesas son convertidas en normas, en estéticas y en géneros: la novela policial, la comedia ligera, la emisión cultural, el documental de viaje, las emisiones de juegos, etcétera, son géneros que contienen instrucciones de lectura, inscritas en la forma misma de los textos y explotables según los códigos de cada universo cultural. A cada género corresponde, por el lado del texto, cierto número de reglas e indicaciones que permiten reconocer cuál es el régimen de creencia propuesto, y, por el lado de la práctica de interpretación, un tipo de imaginario y de disposición interior que posibilita aceptar la promesa y adoptar el régimen de creencia. Así, para entrar en una obra de ficción hay que suspender la incredulidad que podría inspirar la confrontación entre el mundo de la obra y el de la experiencia cotidiana, y aceptar provisionalmente un nuevo tipo de creencia (ficcional).

En los géneros explotados por los medios, particularmente la televisión e internet, las promesas semióticas pueden ser reagrupadas en tres grandes categorías (si seguimos los trabajos de Francois Jost), ${ }^{1}$ y, por lo tanto, en tres regímenes de creencia fuertemen-

1 Particularmente en François Jost (2005, coll. 128). 
te contrastados. Tres solamente: (I) el documento y la información, (II) el juego y la competición, (III) la ficción y la narración. Cada uno de esos tres regímenes de creencia se define por la relación de verdad que tiene con el mundo de la experiencia cotidiana, y esa relación de verdad puede incluso ser objeto de validaciones o de falsificaciones: por ejemplo, el documento y el juego deben poder influir sobre la experiencia cotidiana, cada uno a su manera, mientras que ese no es el caso para la ficción.

Cada uno de esos tres regímenes de creencia mantiene, además, relaciones espacio-temporales específicas con la experiencia cotidiana (pueden estar completamente separados de ella, o estar fuertemente anclados en ella): se sabe que la ficción se coloca como separada del momento y del lugar de la lectura y que eso se traduce, en los escritos de ficción, por una utilización específica de los tiempos verbales. Por lo demás, cada uno de esos regímenes de creencia corresponde a un tipo de valores, a juegos de roles y a reglas de validación propias; para el documento: la nueva información es testimoniada, el aporte de conocimiento validado; para el juego: la ganancia justificada y conforme a las reglas anunciadas; para la ficción: el interés y la verosimilitud continuados y sostenidos hasta el fin, etcétera.

El usuario de los medios entra, pues, en los textos mediáticos premunido de sus instrucciones y de sus pro- mesas definidas por su género. ¿Y qué descubre hoy día? Emisiones de juegos que son transformadas en documentos de viaje; relatos de aventuras exóticas que son de hecho narraciones de juegos y de competiciones; porciones de vida cotidiana que son también aparentemente construidas como juegos, pero donde se aprende pronto que funcionan de hecho como ficciones; documentos que toman prestados sus códigos de géneros típicamente ficcionales, etcétera. El momento más conocido de esta evolución cultural corresponde al nacimiento de la «real $T V$ », a la difusión de la telerrealidad bajo todas sus formas, que impone su propio régimen de creencia (la ficción y la narración escenarizada) bajo la cubierta de otro régimen (el juego y la competición), en situaciones que querrían sin embargo presentarse como documentales y trivialmente cotidianas.

Pero la tendencia es mucho más general, de suerte que, pasando de una cadena a otra, y descubriendo una escena de persecución automovilística, es más y más difícil decidir de golpe si se trata de una secuencia de filme policial (ficción y narración), de un documental sobre el trabajo de la policía (documento e información), o de una carrera de autos (juego y competición); asimismo, un grupo de actores atravesando un río tumultuoso puede pertenecer igualmente a un filme de aventuras (ficción) que a una emisión de deportes extremos y de supervivencia (juego) o a una publicidad para 
un destino o a un promotor de viajes (documento e información). Esta tendencia es más acentuada mientras más se presta el soporte mediático a una práctica fragmentaria, que se llama zapping para la televisión, o navegación para internet.

Entonces hay que comprender que el medio en cuanto tal es portador de un régimen de creencia global y de formas de vida dominantes que vienen a interferir con aquellos y aquellas que están asociados a los géneros textuales propiamente dichos, y fijados en cada cultura particular. El juego, el documento y la ficción se convierten, entonces, en «meta-regímenes de creencia» que son transversales en relación con los de los géneros textuales y que engendran, a la vez, formas mixtas y gran número de combinaciones, y una creciente incertidumbre para el espectador al momento de la interpretación.

El problema ya no es, en efecto, saber si las emisiones de información dicen la verdad sobre el mundo, si los juegos son trucados o fiables, si las publicidades son conformes con la deontología comercial o si los filmes de ficción respetan los códigos estéticos de su género; el problema se plantea más bien ascendentemente, porque lo perturbado y desestabilizado es la elección del régimen de creencia más apropiado. Es fácil comprender que si, frente a un filme publicitario, conviene preguntarse de antemano si se está ante un juego, un documento o una ficción, las condiciones del mensaje publicitario están fuertemente degradadas, y esta degradación solo puede estar a favor de la manipulación de las creencias, es decir, de una estrategia de persuasión que juega con la desestabilización semiótica del intérprete.

\section{Por una ética de los regímenes de creencia}

El juicio de buen sentido, en materia de medios, no es, pues, suficiente. Inquietarse por la influencia de los medios sobre las costumbres, denunciar su poder de difusión, querer controlar la diseminación de las representaciones estereotipadas que vehiculan, todo eso es ciertamente loable, sin duda inevitable, como toda puesta en guardia frente a una capacidad de manipulación de gran alcance. Frente al poder de difusión, los pedagogos y los sociólogos proponen en general soluciones educativas: hay que aprender desde la escuela a reconocer los códigos, a identificar los géneros, a adoptar el régimen de lectura mejor adaptado a cada medio y a cada género.

Pero claramente se advierte que, en el corazón del problema, la hibridación de regímenes de creencia mediáticos contemporáneos obliga a inventar otras contra-estrategias y una ética de los medios que se adapte a nuestro tiempo. Ciertamente, el problema no es nuevo, pero ha cambiado de naturaleza. De ese problema, en efecto, Gustave Flaubert hizo en 1857 una novela, Madame Bovary, en la que el personaje 
epónimo era conducido a la decadencia y al suicidio por haber creído que podía vivir, en la experiencia cotidiana, como se vivía en las ficciones novelescas de las que se nutría abundantemente; la confusión de regímenes de creencia no es, entonces, privilegio de los medios contemporáneos.

Prosiguiendo nuestro análisis, la diferencia salta a los ojos: en el caso de Madame Bovary y de sus semejantes, anteriores o posteriores, la institución novelesca no está en cuestión, solo la fragilidad del intérprete y su probable competencia semiótica defectuosa explican la confusión: madame Bovary no fue engañada por una confusión de regímenes de creencia en las novelas, pero se extravió en la elección del régimen de creencia; en particular, ella recibió el contenido de la promesa ficcional (novelesca) como pudiendo ser transferida y puesta en marcha en su propia experiencia cognitiva y sensible. Más generalmente, y aún hoy en día, los grupos de presión que protestan contra la imagen de la mujer difundida por los medios, contra las costumbres puestas en escena en esos mismos medios, o contra toda suerte de bajezas ideológicas o morales atribuidas a sus autores, practican la misma amalgama y se pierden de la misma manera: todas ignoran (conscientemente o no) la diferencia efectiva y significativa entre los regímenes de creencia, razonan como si los espectadores intérpretes fuesen incapaces de identificar los géneros y los regímenes de creencia, o definitivamente incapaces de ser educados a ese respecto.

Pertenecen igualmente al mismo paradigma de la confusión «patológica» o «transgresiva» los métodos de la publicidad llamada clandestina: un reportaje sesgado para promover una empresa o un servicio se basa, en efecto, en una confusión de creencias y particularmente de modos de persuasión, pero en el interior del mismo régimen, el del «documento-información», y en la lectura crítica del texto mismo podrá ser reconocido el sesgo publicitario. Más insidiosa es la puesta en escena, en la ficción novelesca o cinematográfica, de productos o de marcas; uno se podría escandalizar del procedimiento (por lo demás, reglamentado), pero la presencia de un producto o de una marca procedente de la experiencia cotidiana no es, sin embargo, semióticamente elocuente, tampoco más anormal que toda otra forma de «apoyos» realistas: es, en efecto, un procedimiento tan antiguo como la ficción, que consiste en incluir en ella hechos $\mathrm{u}$ objetos de los que se puede tener experiencia directa o de los que se puede atestiguar la existencia por testimonio; no hay ahí cambio de régimen de creencia sino una forma de «mención» interna, un procedimiento retórico codificado y del cual, en principio, nadie debería ser víctima, destinado a otorgar un valor de autenticidad al universo de la ficción. La autenticidad no es la realidad sino cierto efecto de referencia inmediata y simulada a la realidad. 
En el caso de los medios contemporáneos, las cosas ocurren de otra manera, porque la institución practica sistemáticamente la hibridación e induce a la confusión de regímenes de creencia; y no es el intérprete el que sería frágil, incompetente o aturdido. En el caso de la telerrealidad, por ejemplo, los comportamientos que son presentados como cotidianos y documentados son, de hecho, construidos de manera ficcional, están elaborados con un guion a base de tramas argumentales, y son asumidos por personajes que han sido seleccionados como lo son los actores de la ficción. Más aun, las reglas de exclusión progresiva de los participantes, que se supone remiten al universo de los juegos y de la competición, forman igualmente parte de la trama argumental, tal como lo son, por ejemplo, las alternativas argumentales y textuales que son propuestas en los relatos interactivos, los cuales explotan bases de datos numéricas. En suma, esas emisiones de la telerrealidad toman todo su dispositivo del régimen de la ficción, apropiándose de todas las apariencias de géneros propios del documental y del juego.

\section{¿Ética o estrategia?}

El rol del semiotista no es definir una norma de conducta, o preconizar tal o cual prescripción moral. Es observar, comprender e identificar las «zonas críticas», los lugares problemáticos y los puntos de intervención que son susceptibles de conducir a la solución de los problemas. En la ocurrencia, la zona crítica es la hibridación de los regímenes de creencia; el lugar problemático es la existencia de regímenes de creencia propios de los medios globalizados, e independientes de los que los géneros textuales tradicionales proponen en cada cultura; el punto de intervención es probablemente la congruencia de las formas de vida: en esos procesos, en efecto, la congruencia entre los niveles de análisis y los diferentes tipos semióticos de cada cultura, congruencia que hemos definido como propia de las formas de vida, es puesta ahí en crisis. La existencia de una forma de vida reconocible es, en efecto, una condición para que el usuario de los medios pueda asumir o tener a distancia, aceptar o rechazar con conocimiento de causa los valores, las situaciones y los roles que le son propuestos, y la hibridación sistemática que constatamos no puede sino descalificarlo como sujeto responsable de sus elecciones.

Y si se recuerda que la congruencia de una forma de vida es la clave de una identidad fuerte para una marca, para una cadena de televisión o para un sitio de internet, entonces ese punto de intervención se convierte en estratégico para el medio mismo. La confusión sistemática entre los regímenes de creencia hace, en efecto, ilegible la organización de la rejilla de una cadena de televisión, puesto que hace vacilar la distinción entre géneros textuales y tipos de programas que son además distribuidos cuidadosamente durante el día y a lo largo de la semana. 
Y esa confusa hibridación no es, sin duda, extraña al hecho de que, hoy en día, al menos en lo que concierne a los medios generalistas, la identidad misma de las marcas, de las cadenas y de los títulos es más y más indistinta. Sin identidad reconocible, una marca no puede enunciar legítimamente; o, más simplemente, no puede adoptar una clara posición de enunciación. Retornando al punto precedente: sin enunciador identificable, el enunciatario no sabe cómo tomar posición; el yo construye al tú, y recíprocamente, y si uno de ellos falta, el sistema de la instancia de enunciación vacila.

No es fácil decidir, en ausencia de investigaciones sistemáticas, en profundidad y sobre un largo periodo, si el fenómeno observado es una tendencia durable o una simple transición pasajera. Se puede, en efecto, imaginar que, en esa zona periférica de las culturas, donde operan las transiciones y las traducciones, los regímenes de creencia mediáticos estén en trance de «dejar» el nivel de análisis de los géneros textuales; y de que vayan a anclarse en el de las formas de vida. Esta hipótesis no es absurda, ya que de cierta manera, los soportes, las prácticas y los usos sociales están siempre en el origen de los géneros textuales, y solo después de su fijación institucional aparecen como propiedades textuales, propiedades llamadas "genéricas». $\mathrm{Si}$ tal fuese el caso, observaríamos actualmente una fase confusa en la que se superpondrían reglas pertenecientes al antiguo sistema y las propias del nuevo sistema.

\section{Para terminar: esas creencias que nos instalan en el mundo}

Sin embargo, tendencia durable o transición pasajera, esta confusión por hibridación conlleva el mismo riesgo para nuestros contemporáneos: el de ver que se les impone, o el de imponérselo ellos mismos, en un deseo de clarificación, de simplificación o de reaseguramiento, un régimen de creencia único. Orwell había encontrado un nombre propio para esa reducción totalitaria: Big Brother; Big Brother, en efecto, es un medio, y satisface las condiciones de definición de un medio, es comprendido por su capacidad para abarcar y reorientar todos los tipos semióticos de una cultura. Pero nuestra época produce otros, de la misma naturaleza, y aunque no sean definidos o aprehendidos como medios, son igualmente portadores de un régimen de creencia único y de una forma de vida totalitaria: la economía financiera, por tomar un ejemplo de actualidad, es uno de esos «integrismos» semióticos que nos son impuestos (o que nosotros nos imponemos) como la explicación última de todas las cosas, al mismo tiempo que el filtro verdadero de nuestra relación con el mundo.

El semiotista no puede sino defender la diversidad de regímenes de creencia, 
pero una diversidad suficientemente contrastada. Tres regímenes solamente en los medios contemporáneos, es ya demasiado poco; pero es peor aun si contribuyen a la confusión por hibridación. Hay que militar a la vez por la diversidad de los regímenes de creencia y por la clara distinción entre cada uno de ellos, como se puede militar por la diversidad biológica y la clara identificación de cada una de las especies.

La diversidad de regímenes de creencia es la garantía de la plenitud semiótica de nuestra relación con el mundo. Solo estamos en el mundo, justamente, en la medida en que creemos en eso que nos propone, en que creemos que él soporta la significación de nuestro estar en el mundo. $Y$ siendo a la vez el mundo extremadamente diverso $y$, sin embargo, sentido como único, tenemos necesidad de la diversidad de regímenes de creencia y de su clara adaptación a cada situación portadora de sentido, para sentir la unidad de nuestra relación con el mundo: desde la «fe perceptiva» que nos hace tomar por verdaderas nuestras percepciones cotidianas, hasta la fe religiosa, que nos abre, en el sentido mismo de la experiencia cotidiana, la posibilidad de otros mundos, pasando por la creencia ficcional y la confianza en las reglas de la competición, solo somos, semióticamente hablando, creencias diversas y totalmente específicas.

Si hiciera falta enunciar una recomendación propiamente semiótica, sería, por tanto, esta: preservar, desarrollar y dinamizar la diversidad de nuestros regímenes de creencia culturales. Y esa es, precisamente, la condición para que las formas de vida que ellos soportan puedan ser percibidas y asumidas como formas de vida. Desde un punto de vista semiótico, en efecto, una forma de vida no tiene existencia sino por contraste, al menos por el contraste de una figura diferente y resaltante sobre un fondo de consenso; las formas de vida solo estructuran nuestra relación con el mundo por su capacidad de oponerse y de transformarse; $y$, gracias a sus contrastes distintivos, por solicitar nuestra elección.

Solo podemos asumir nuestras formas de vida en la diversidad y de ese modo podemos asignarles una significación por contraste. Nuestra vida solo tiene sentido en la contradicción y en la posibilidad de elección, y los medios contribuirán a crear ese sentido si plantean y despliegan ese potencial de contradicción y de contraste. 


\section{Bibliografía}

Lotman, I. (1999). La sémiosfère. Tartu, coll. «Los lenguajes de la culLimoges: Pulim. Traducción de A. tura rusa», 1966.

Ledenko, establecida a partir de las Fontanille, J. (2008). Pratiques sémiotipáginas 163-295 de la obra original de Lotman El universo del espiritu. Moscú: Ediciones Universitarias de ques. París: PUF.

Jost, F. (2005). Comprendre la télévision. Coll. 128. París: Armand Colin.

Traducción: Óscar Quezada Macchiavello. Título original: «Médias, régimes de croyance et formes de vie», 2013. 